\title{
Students' Views on Strategic Note-taking and its Impact on Performance, Achievement, and Learning
}

\section{Issa I. Salame}

Asst. Prof., The Department of Chemistry and Biochemistry and the School of Education, The City College of New York of the City University of New York, USA, isalame@ccny.cuny.edu

\section{Ashley Thompson \\ B.S., Psychology, The City College of New York, USA, athomps002@citymail.cuny.edu}

\begin{abstract}
Strategic note-taking is beneficial to students in that it provides a certain way a student can learn, and it can help a student perform better in courses. Taking strategic notes is seen as an important skill that is needed in a college setting. Strategic note-taking involves active listening, processing information, and writing. It is hypothesized that a student's strategic and extensive note-taking can yield a higher performance and achievement. Proper note-taking is a skill that many college students lack. The objective of this research study is to examine whether strategic-note taking improves science, engineering, and mathematics students' performance, achievement, and learning. A survey research was done and collected from 160 students of the City College of New York. The survey questionnaire included Likert-type and open-ended questions, which served to understand the students' views, perceptions, and beliefs about the benefits of strategic note-taking. Data collected from this research project show that note-taking improves students' recall of material, increases students' understanding of the content, assists in preparation for examinations, and improves their overall grades. Note-taking plays a role in gaining knowledge, learning and success in courses. Also, it is noteworthy that our data show a correlation between note-taking and grade point average (GPA); students who take better notes have higher GPAs.
\end{abstract}

Keywords: note-taking, student performance, study skill, achievement, learning

\section{INTRODUCTION}

The transition from high school to college is not a smooth road. Classroom sizes are bigger, the students also must adapt to the way their instructors teach, and little support is provided from instructors. Note-taking plays an important role in formal learning

Citation: Salame, I. I., \& Thompson, A. (2020). Students' Views on Strategic Note-taking and its Impact on Performance, Achievement, and Learning. International Journal of Instruction, 13(2), 1-16. https://doi.org/10.29333/iji.2020.1321a 
environments (Williams \& Eggert, 2002). Note-taking is especially important in learning. At the college and university level, many instructors do not go over the importance of taking notes during lectures (Grabe \& Christopherson, 2005). Proper note-taking is a skill that many college students lack (Suristky, 1992), even juniors and seniors, not just freshmen. Many students take poor notes, especially in lecture as they would only record about $25 \%$ of lecture notes (Boyle, 2011). If students can take notes efficiently and effectively, then it is likely that the overall performance in the course will improve as well. The problem with this, is that many students do not know how to strategically take notes. Even though, science students and instructors are partial to notetaking as a learning strategy (Weiss, 2002), students still have deficiencies in notetaking.

Students who takes poor notes are more likely to struggle in courses and their course performance might suffer. Strategic and extensive note-taking improves students learning as well as achievement in a class. Research suggests that active process of strategic note-taking seems to improve student learning (Prince, 2004). According to one study, note-taking and reviewing have a substantial positive impact on students' learning (Kobayashi, 2006). As mentioned earlier, many students do not know how to take effective notes. Note-taking, however, is the most common method used by students to learn information from content lectures (Boyle, 2011). It is an important representation of the knowledge transaction, as it is seen as a tool for cognitive processing, and this is one of the reasons why students believe they are better equipped to remember things from a lecture when they write things down.

One of the major benefits in taking notes, is that the students can be actively engaged in a lecture by listening to the instructor for important knowledge, writing it in their own words. In a recent study, researchers found that note-taking improved learning and increased understanding through active engagement in note-taking with the content (Bohay et al., 2011). When students actively listen and write down important information, it allows them to cognitively process it, which in turn allows them to better understand the information that they are learning. This is an excellent skill to have, as some students will just write and not cognitively process the information that they are writing. That being said, although note-taking is effective, students lack the strategic skills needed to benefit them from note-taking in content-heavy classes (Boyle, 2011). Di Vesta and Gray (1972) proposed a hypothesis that deals with encoding note-taking and whether it enhances the encoding of lecture or text information.

Strategic note-taking forms improve problem-solving and self-explanation and lead to enhanced learning and understanding (Trafton \& Trickett, 2001). Students are well aware of the importance of the role that lecture note-taking plays in their educational experience (Dunkel \& Davy, 1989). Furthermore, Strategic note-taking is considered a useful learning strategy that improves problem-solving skills and its benefits include making sense of data and not just memorization and recall (Trafton \& Trickett, 2001). According to Moos (2009), note-taking without deep attention or modifications restrains meaningful learning; that is transmitting course's content from one form to another textbook to notebook - without changing and internalizing it reduces learning. 
In 1939, Charles Edgar Finch did a study survey that listed 19 study aids and was submitted to over 2,000 students who were asked to vote which study aid helped them the most. Note-taking received more votes than any other aid that was listed (Finch, 1939). Approximately 700 students voted that learning how to make strategic notes would be most helpful in their learning and help to advance their study habits. This holds true to this day as Boyle (2011) explained that learning occurs through three main processes of thought note-taking. In the first process, students write down incoming materials and see which content is relevant or irrelevant. The second one being that students organize relevant information and create mental representations. The third process is that students relate information that they learned, with existing knowledge from their memory (Boyle, 2011). This is how students are able to make strategic notes; by simply deciding which material is important through lectures, paying attention to what the instructor is saying, being able to relate what was learned to prior knowledge, and lastly being able to incorporate it into their long-term memory. Note-taking promotes the building of connections among lecture and improves memory (Mayer, 1984). Furthermore, the data revealed that note-taking impacts our memory. The major results of this study show that note-taking and review combined is way more effective on learning (Kiewra, 1989). Note-taking leads to higher performance in class, as it positively impacts memory and one is able to recall more, which is useful for future exams (Kiewra, 1995). Research supports the notion that note-taking positively impact students' working memory (Olive \& Piolat, 2002).

The key to making strategic notes is learning how to use strategies that can allow an individual to filter and organize incoming information during lecture, so that it is translated into meaningful units of knowledge (Makany et al., 2008). This is hugely beneficial to students because having organized and well-structured notes directly related to exam scores and engaged learning (Kiewra et al., 1991). It is clear why most instructors stress the need to be an active listener during lectures. If students are actively listening, then they are able to decipher which information can be used and which information is not necessary for the long run. When students take strategic notes, they record notes through linking background knowledge, summarizing different incoming ideas, knowing vocabulary, knowing the main points presented in lecture, and understanding the vocabulary that is being used. This can translate to success in students' learning and would impact their overall performance.

In an experiment involving 76 middle school students, researchers wanted to see if students who use their strategic note-taking, would record more important lecture material (Boyle, 2011). As hypothesized, the results showed that students who used strategic note-taking, were more successful than traditional note-takers. Strategic notetaking led to an improved performance, understanding, and recall of the material. Success in classes, and higher class performance for students, is a major advantage due to strategic note-taking. Recent studies provided data suggesting note-taking quality positively impacts memory and test performance (Peverly \& Sumowski, 2011) and quality note-taking leads to improved memory performance (Mueller and Oppenheimer, 2014).

International Journal of Instruction, April $2020 \bullet$ Vol.13, No.2 
Some researchers might even argue about the function of note-taking and whether or not it serves as an aid to remembering information or if it is a product for future review of lecture material (Van der Meer, 2011). Either way, it is still a beneficial tool that can be used to improve grades in a course, as it is a means of understanding. According to research, verbatim not taking does not serve the students well, it is paraphrasing and summarizing that lead to improved understanding and learning (Bretzing \& Kulhavy, 1979). Students who copy verbatim in lectures exhibit little involvement in the content and this hinders learning (Laidlaw et al., 1993). Students who internalize, paraphrase, and summarize during note-taking show better comprehension of the material covered (Lonka, 1997).

The problem is that for many university students, it could just be a case where students are writing down everything rather than actively processing the information and making sense of what is being said in the lectures. Recent research showed that verbatim notetaking of teaching content was found to negatively impact learning, whereas prior knowledge and positively impacts learning and knowledge acquisition (Trevors et al., 2014). An individual has to listen, pay attention, process information, and then write; many students may have difficulties in doing so. The issue isn't that students do not think note-taking is beneficial, the issue is that they do not know.

In note-taking, students should definitely have a "quality over quantity" approach to it (Castello \& Moreno, 2005). What students need to understand is that taking effective notes does not only entail writing down words, it is a means of making sense of the material that is being taught and providing understanding for future use. In this new generation though, note-taking through handwriting has become less popular (Sutton, 2000). The major difference between how it was in the past generations and now, is that many people did not have access to the internet as much. In this day and age, notes are provided online by lecturers, as opposed to back then, when students had to read huge encyclopedias and make their own notes (Van der Meer, 2011). As this is the information and technology age, this influence has significantly changed the way students take notes as they rely on web notes more so than reading textbooks and taking their own notes.

Note-taking is considered one of the pillars of formal classroom learning where it can improve recall and memorization when participants are engaged in understanding from the teacher (William \& Eggert, 2002). Strategic note-taking is a technique used to improve knowledge acquisition (Kiewra et al, 1991). Although, some research suggests that students have difficulty taking notes (Suristky, 1992). Being engaged in the process of note-taking promotes recognizing and organizing important content. Note-taking has the advantage of having the participants write, elaborate, assemble and understand information presented during lectures (Bonner \& Holliday, 2006). Strategic note-taking involves the ability to appropriately identify main ideas, transcription fluency - the rate of written word production, and working memory, which are related to test performance (Peverly et al., 2007). Identification of main ideas significantly impacts learning and remembering of information (Kintsch, 1998). 
One study found that only a small fraction of students are strategic note-takers, who take notes in a conscious and intentional manner, producing a meaningful learning situation and improving construction of knowledge through epistemic note-taking (Castello \& Monero, 2005). Students who struggles with taking strategic notes are hindered from knowledge acquisition due to poor note and reviewing them is not beneficial to their learning (Kiewera, 1989). When students self-explain, reorganize material, and problem solve during note-taking, they will perform better than just copying verbatim (Spires, 1993). Note-taking is a deliberate activity that involves writing down information after sorting, evaluating, and comprehending it (Piolat et al., 2005).

Note-taking nurtures knowledge construction which is considered a prerequisite for meaningful learning and instructors aim to have their students being actively involved in the learning process as opposed to being passive vessels (Stefanou et al., 2008). Furthermore, Strategic note-taking and prior knowledge have shown to positively impacted college students' performance on exams more so than self-regulatory skills (Peverly et al., 2003). It is argued that even though note-taking is a linguistic activity, it does involve visual and spatial activities through use of eyes and organization of text on the page and by organizing text in accordance to a specific semantic structure (Olive \& Passerault, 2012). This visual and spatial activities improve the visual and spatial working memory which improves learning (Olive, 2012).

The fact of the matter is, in order for students to actually think about taking proper notes, they have to know the aims of their note-taking. This means that they have to understand the conditions where they would need to apply what they are learning from note-taking; For example, if they are preparing for an exam or an oral presentation (Hattie \& Biggs, 1996). Students learning how to take strategic notes believe it is important to their learning (Kiewra et al., 1987). If they know how to take proper notes, then they will be better equipped to learn and fully understand what is being taught to them. Having good notes can help in retaining more information, for when students would really need it, like in exams or for presentations.

\section{METHOD}

Our research hypothesis was done under the principles of past studies elaborated on in this paper, such as the study done by (Kiewra, 1989 and Kinshuk, 2009). The predictions for this experiment, is that students who are enrolled in classes and able to take strategic notes, will have a higher achievement and success in their courses. We wanted to examine the impact of strategic note-taking on students' performance, achievement and learning. When students are proficient in taking concise notes in a strategic manner, are they more likely to learn, achieve and have higher grade point averages (GPAs)?

We decided that one way to answer this research question was to have collect data through a questionnaire given out to The City College of New York students. A survey research was done and collected from 160 students of the City College of New York. Majority of students were Science, Technology, Engineering and Mathematics (STEM) majors. The survey included Likert-type and open-ended questions. These questions 
were precisely based on testing to see how students take notes and how beneficial they believe note-taking is. The survey was in fact anonymous and included declared majors and GPAs. The participants were informed of their rights and the survey was administered, collected, analyzed and stored according to the Internal Review Board procedure. The declared majors and GPA were needed for statistical purposes. We needed the declared major, to see the percent of majors we had in our sample size and we requested the GPAs to examine if there is a correlation between note-taking and GPAs. Data were collected in the Fall 2018 and Spring 2019 semesters.

The Likert-type section had a 5-point scale which included: strongly disagree (1), disagree (2), neutral (3), agree (4), and strongly agree (5). In the next section of the survey, there were three open-ended questions and these questions served the purpose of seeing how beneficial note-taking is for students, as well as what were the different purposes of their notes. This was important as we wanted to see how students were using their notes, whether it was for exam preparation, memorization, learning, internalizing, processing, and other meanings. For two of the open-ended question we used a rubric to score each answer based on a 1 to 5 scale. For the final question, we compiled all the answers and placed them into categories and were able to obtain a pie chart for the results.

Data was collected in the form of surveys from 160 participants from City College of New York students, with a wide variety of majors. In order to fully understand the data, we needed to find a reasonable method to analyze the data. For each of the Likert-type questions, we used a 5-point scale. Thus, if a student put 'strongly agree', that would correspond to five points for that question. After which, the averages were taken for each of those questions. After the responses were scored, they were all tallied up and averages were taken. The use of rubrics was especially important when scoring the responses because it helped in keeping the scores in check since these were evaluated by the two co-authors independently. A score of 1 is applied if there was an overall negative response, a score of 3 is applied for a neutral answer, and a score of 5 is applied when the student gave an overall positive response.

Participant surveys were divided into three groups based on 3 different GPA groups: students who had a GPAs less than 2.99, students who had GPAs between 3.00 to 3.49, and lastly, students who had GPAs more than 3.50. It was vital to our research that we grouped students in this manner because this way, we would be able to examine if a trend exists between note-taking and GPAs.

\section{FINDINGS}

Most of the participants were STEM (Science, Technology, Engineering, Mathematics) students. This includes Biology majors, Engineering majors, and so on. For social sciences, majority of students were Psychology majors. Our research findings reflect learning achievement and learning performance as measured by grade point averages. 


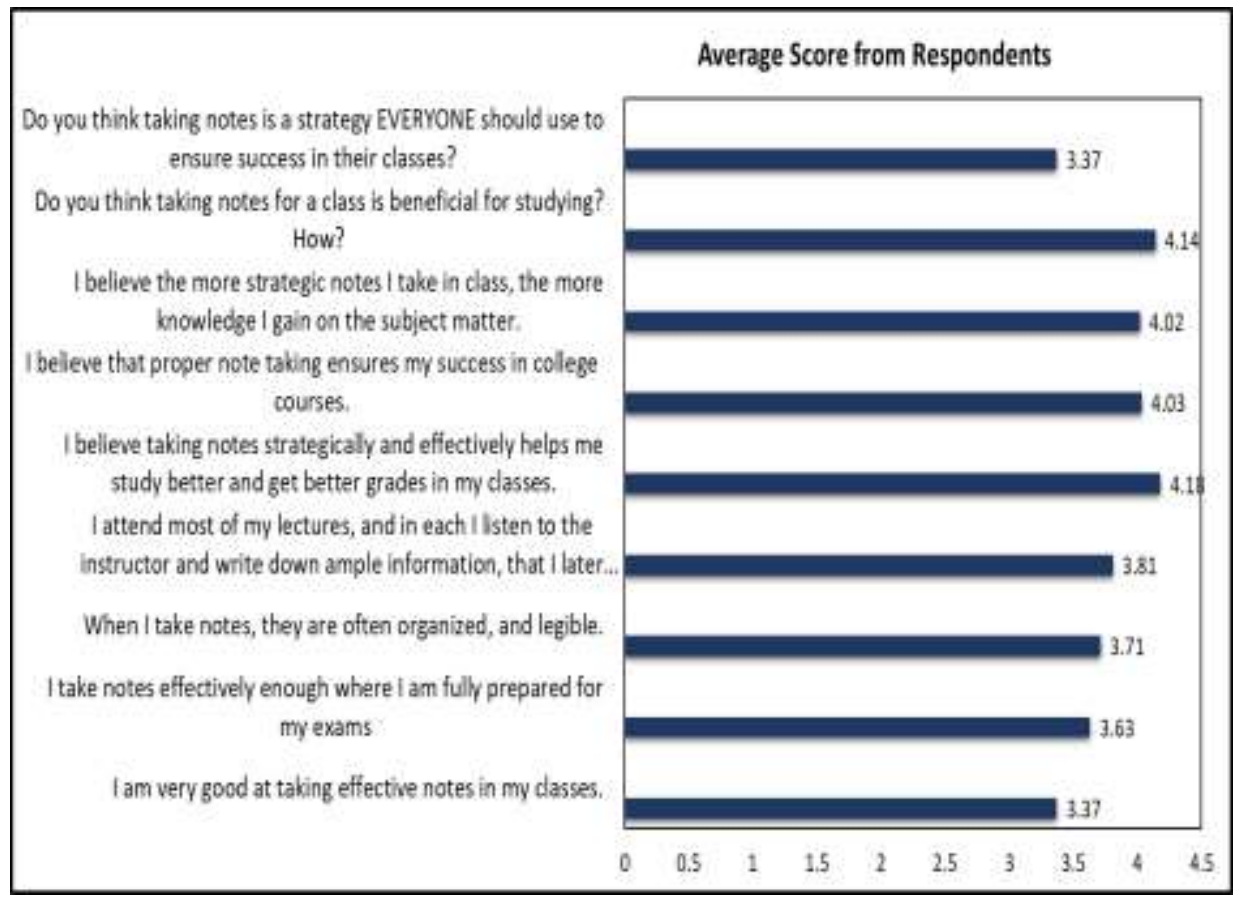

Figure 1

Averages for the Answers for Each of the Likert-Type Questionnaire

Summarized above is the overall averages, including all 160 students. These results are related to learning achievement. The averages are based on the 5-point scale for the Likert-type and Open-ended questions. These scores show an overall positive reaction toward taking good notes. Students agree that Note-taking is an important strategy for ensuring success in classes, beneficial to studying, and gaining knowledge. The first Likert-type question aimed to understand the students' general view of note-taking and how it can help not just them, but other students as a whole in classes. The second and third Likert-type question was used to see if students understood why note-taking is so important. It was important to know if whether or not the students themselves believed taking notes benefitted them in a way where it was promoting knowledge and helping them in their classes. The fifth and sixth Likert-type questions were used to see if students understood what strategic note-taking was because regular note-taking and strategic note-taking are different. Attending lectures is also important in strategic notetaking because students need to actively listen to the lecturer and understand which material is important. The last three Likert-type questions were used to see if students were taking organized notes and whether they were using it to improve learning and comprehension.

Displayed in figure 2 is the results obtained from the three GPA sections for all Likerttype questions. Our data show there is a positive relationship between GPA and Note- 
taking. Additionally, our data show that note-taking improves learning and achievement. Therefore, note taking improves both students' GPAs and learning achievement. According to the data and as can be seen clearly in figure 2, there seems to be a correlation between students' GPAs and their attitudes towards note-taking and how it impacts their success in classes, learning, and gaining knowledge. There is a clear upward trend in averages for each Likert-type question, as the GPAs increase. The data support the notion that strategic note taking improves learning performance as measured by GPA.

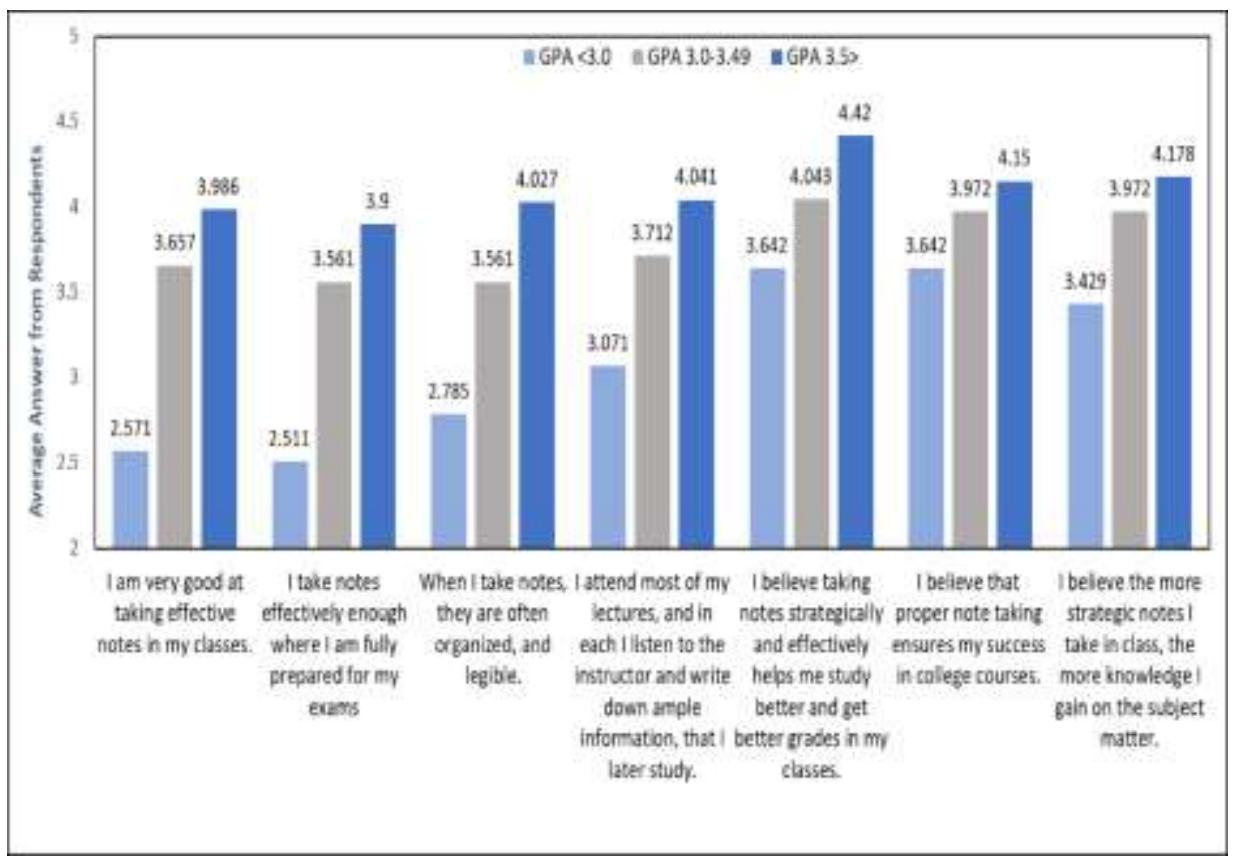

Figure 2

Averages for the Answers for Each of the Likert-Type Questionnaire Related GPA

Figure 3 shows the results for two of open-ended questions. Results from GPAs less than 2.99 are shown in light blue, 3.0-3.49 are shown in gray, and 3.5 and above are shown in dark blue. According to the data, both questions show a correlation between note-taking and GPAs. Furthermore, students overall think that note-taking are beneficial to them. The more successful students as measured with GPA the more they emphasize the importance of note-taking strategy for success. 


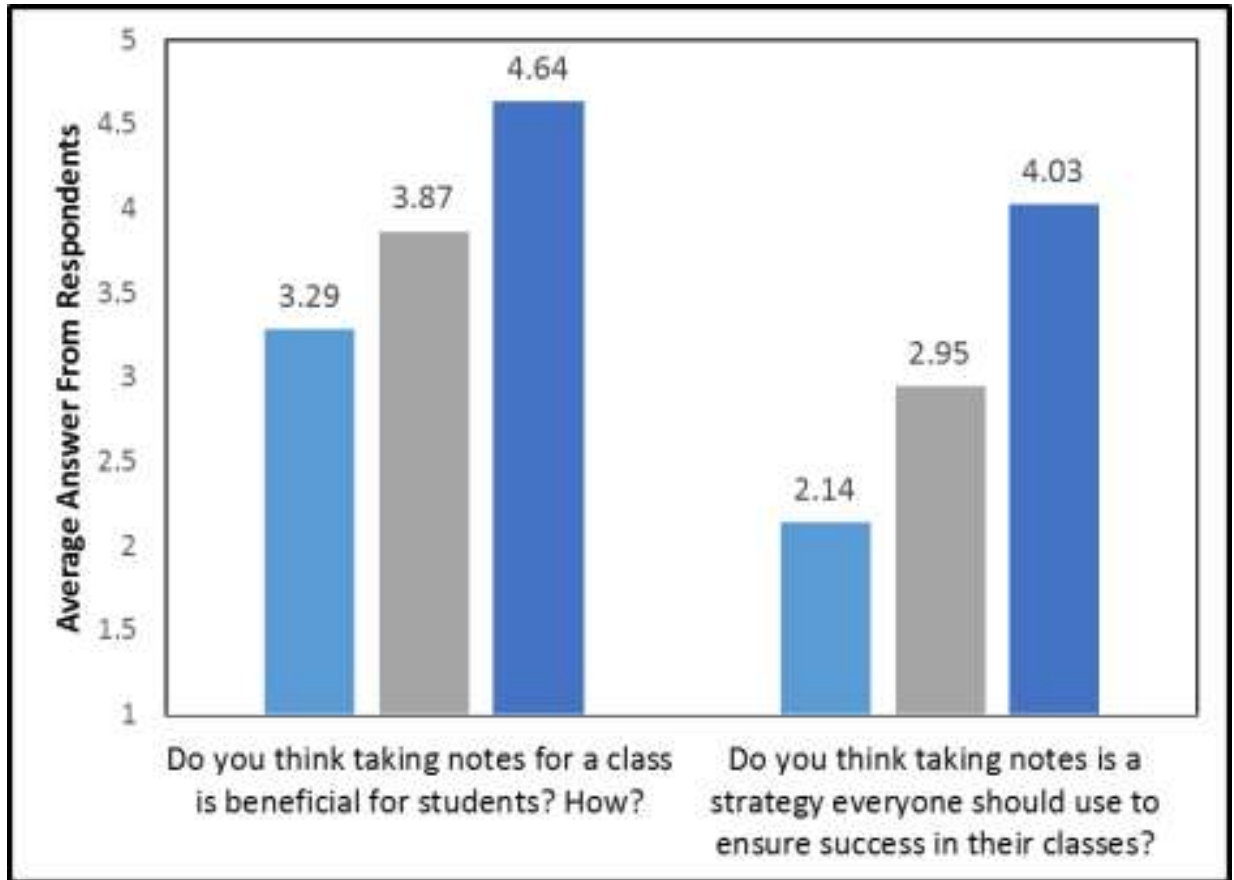

Figure 3

Averages of the Short-Answer Responses that were Numerically Scaled Using a Rubric

There were numerous unique answers, and they were grouped into these different categories. These are depicted in figure 4. According to the data, the majority of the participants used note-taking strategy to improve their memory of the material. A significant number of students, $24 \%$, use note-taking as to understand the content, and $23 \%$ of students use note-taking as a way to prepare for exams. We should mention that about $12 \%$ of students use note-taking to improve grade and performance in class. Notetaking is an effective learning strategy and has a positive effect on college students' learning performance as it increases interest in content, comprehension, and recall (Van Meter et al., 1994). Good notes contain personal meaningful information (Van Meter et al., 1994) which serves as useful retrieval reminders (Carrier \& Titus, 1979). 


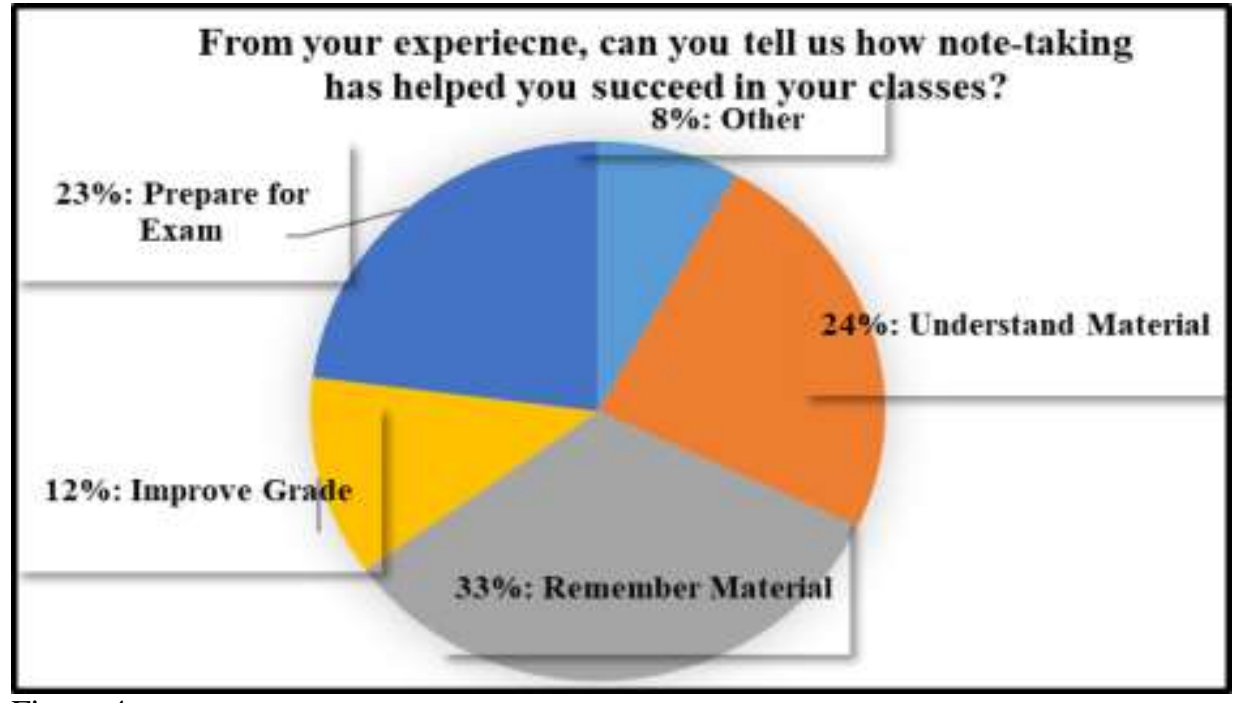

Figure 4

The Pie Chart Above Shows How Note-Taking Helps Students Succeed

\section{DISCUSSION}

Results from figure 1, were used to see if there was a difference in note-taking habits among students in different majors. It should be noted that $73 \%$ of participating students were in STEM majors, and $27 \%$ were in a social science major. Our data show that note-taking habits did not correlate with a major, but rather that as GPAs got higher, it correlated to more positive note-taking strategy. Our data suggest that students had an overall positive response toward taking strategic notes. The data suggest that majority of students agreed that taking strategic notes, is in fact beneficial in improving class performances. Note-taking provides an opportunity for students to engage in higher order cognitive skills because note-taking requires the student to be attentive to the lecture, actively listen to the instructor, decipher information, and paraphrase it (Steimle et al., 2009).

The data analysis presented in figure 2 provides an answer to whether note-taking strategy is correlated GPAs. An upward trend in the averages as GPAs increase can be seen in the diagram. For students who held a GPA below 3.0, averages for each Likerttype and open-ended questions where shown across the board to be mostly below 3.0 out of the 5- point scale. Each Likert-type statement specifically tied into why students take notes, how they take notes, and whether or not it is beneficial. Data suggests that these students did not take proper and strategic notes, did not think it was very beneficial to their learning, and overall, did not see the need to take notes.

On the contrary, looking at students with GPAs between 3.0 and 3.49, there is a significant difference. These students had a more positive view of taking strategic notes and using them. The averages for this group were much higher than the former. Students 
with GPAs above 3.5, had the highest averages across the board, and this is the data we wanted to find in order to support our hypothesis. These students agreed that they took effective notes in class, and used them for exams, enough that they would be able to get higher grades leading to higher performance. These students believe taking strategic notes are very beneficial, especially when studying for an exam, and as a result, they were more successful in their classes; this of course shows because they have the higher GPAs. Based on this data alone, it is safe to say that when students are able take very strategic notes and use them to their benefits, it will yield higher performances in classes, which in turn improves their GPAs. This is consistent with other research where in a recent study, students who were told that they would not be given handouts and thus took their own notes, performed better on post-lecture quizzes. Note-taking helped improve their learning and outperform their peers (Khan et al., 2013).

As said before, authors like Boyle and Ganske believe most students lack note-taking skills and cannot use them to their benefit in content-heavy classes. It is an issue because if students are not taking notes properly and just writing anything that is presented to them, they are not partaking in strategic note-taking, as they are not actively listening and deciphering relevant from irrelevant information (which is important in strategic note-taking). Note-taking involves listening, filtering, organizing, integrating, and internalizing of what is read and heard (Brazeau, 2006). Note-taking is not an easy exercise and it demands understanding and choosing information correctly to be recorded (Piolat et al., 2005). It is strategic note-taking that will enable a student to learn the material that is being presented to them, not aimlessly note-taking. Based on the data analyzed, majority of students do know how to take strategic notes and that is mostly common in students with higher GPAs. Students with lower GPAs do not know how to take strategic notes, nor do they find it useful to take notes on a whole, based on our data. Thus, it cannot be expected of them that they would end up doing well in their classes. Perhaps the idea of implementing note-taking classes in schools should be more pronounced. That way, students know how to effectively take notes and as a result, are better prepared for college classes. It is important that these students learn it in high school, so that when they are in college, they are more prepared for the type of classes that would require them to take strategic notes and thrive in college.

It is also beneficial for students to have very well structured and organized notes as it is positively correlated to higher scores on exams and a more engaging, active kind of learning. Strategic-note taking is an important tool in learning which allows students to arrange information and construct mental representation of the material (Bui et al., 2013). This was posed as a Likert-type question which ask students if their notes are often organized structured. Students with higher GPAs had the highest average for that Likert-type question which supports the Kiewra's theory that structured notes are correlated to higher academic performances (Kiewra et al., 1991).

Majority of students use their notes in order to remember material. This data is supported by other research in the field (Boyle, 2011; Kiewra, 1995; and Makany et al., 2008). This is not a surprise based on previous research done on note-taking and how it serves our memory. Figure 4 shows that students also use their notes for understanding 
material, preparing for exams, and improving grades. It is important to note that these all go hand-in-hand. When students understand the material, they are also able to better remember the material and that enables them to be more prepared for exams. If they are more prepared for exams, they would get higher and more improved grades. A further study on this could be what kind of note-taking would promote better learning; whether it be handwritten notes, typing notes or both. How handwritten notes affect memory has been a topic of discussion more recently due to increased technology (Mueller \& Oppenheimer, 2014). More future research on this would be useful in understanding further how note-taking in general, impacts our memory.

While our results support our hypothesis that note-taking is correlated to higher performance in classes, there still may be more skepticism around the general need for note-taking; many believe most students take notes because it is the typical thing to do, as opposed to doing so for later review and memorization. Students should be encouraged to learn the value of strategic note-taking and find the balance between taking useful notes easily and efficiently (Moore Stacy \& Cain, 2015). Perhaps, students who want to get higher grades, know that note-taking is very important to their overall performance in classes. Either way, based on our study, the end result is clear, that taking strategic notes leads to higher academic performance. To take this study further, one can see the involvement of learning styles can affect the way students take notes, study their notes, and whether its involvement along with taking strategic notes, can aid student performance in classes. Learning styles are important to how a student learns, as this is their individualized, unique way of understanding material, and so it would be useful to see its overall impact and involvement in note-taking.

\section{CONCLUSION}

Strategic note-taking is an important tool for students to learn and succeed in their academic careers. Taking strategic notes involves active listening, processing information, and writing. We believe that students internalize the information when taking notes strategically. Our research findings can be summarized in two key results: (1) note-taking improves students recall of material presented by instructors, increases students understanding of the content, and assists in preparation for examinations, and (2) improves their overall grades. Students underscore the benefits of note-taking. Notetaking plays a role in gaining knowledge, learning and success in courses. Our most significant finding is that there is a direct relationship between note-taking and students' GPAs. The higher the students' GPAs the more positive their views are of note-taking, its importance, and its role in learning and achievement.

Strategic note-taking is an important tool for students' learning, retention, and success. Because of the importance of note-taking on students' success, memory, learning, and understanding, more emphasis should be placed on the topic. Note-taking is a skill that can be taught as part of freshman orientation that most colleges and universities provide to their students. Our results and data encourage universities and colleges to take active roles in teaching and nurturing students' note-taking abilities to improve their learning and increase their success rates. 


\section{REFERENCES}

Bohay, M., Blakely, D. P., Tamplin, A. K., \& Radvansky, G. A. (2011). Note taking, review, memory, and comprehension. American Journal of Psychology, 124(1), 63-73. doi:10.5406/amerjpsyc.124.1.0063.

Bonner, J. M., \& Holliday, W. G. (2006). How college science students engage in notetaking strategies. Journal of Research in Science Teaching, 43, 786-818. doi: 10.1002/tea.20115.

Boyle, J. (2011). Thinking strategically to record notes in content classes. American Secondary Education, 40(1), 51-66.

Brazeau G.A. (2006). Handouts in the classroom: Is note-taking a lost skill? American Journal of Pharmacy Education, 70(2), 1-6. doi: 10.5688/aj700238.

Bretzing, B. H., \& Kulhavy, R. W. (1979). Notetaking and depth of processing. Contemporary Educational Psychology, 4, 145-153. doi: 10.1016/0361476X(79)90069-9.

Bui, D. C., Myerson, J., \& Hale, S. (2013). Note-taking with computers: Exploring alternative strategies for improved recall. Journal of Educational Psychology, 105, 299309. doi: $10.1037 / \mathrm{a} 0030367$.

Carrier, C. A., \& Titus, A. (1981). Effects of notetaking pre-training and test mode expectations on learning from lectures. American Educational Research Journal, 18, 385-397. doi: 10.3102/00028312018004385.

Castello, M., \& Monereo, C. (2005). Students' note-taking as a knowledge-construction tool. L1-Educational Studies in Language and Literature, 5(3), 265-85. doi: 10.1007/s10674-005-8557-4.

Finch, C. (1939). Building better study habits. The Journal of Education, 122(4), 131132. doi: $10.1177 / 002205743912200412$.

Di Vesta, F. J., \& Gray, G. S. (1972). Listening and note taking. Journal of Educational Psychology, 63, 8-14. doi: 10.1037/h0032243.

Dunkel, P., \& Davy, S. (1989). The heuristic of lecture notetaking: Perceptions of American \& international students regarding the value \& practice of notetaking. English for Specific Purposes, 8, 33-50. doi: 10.1016/0889-4906(89)90005-7.

Ganske, L. (1981). Note-taking: A significant and integral part of learning environments. Educational Communication and Technology, 29(3), 155-175. doi: 10.1007/BF02766518.

Grabe, M., \& Christopherson, K. (2005). Evaluating the advantages and disadvantages of providing lecture notes: The role of Internet technology as a delivery system and research tool. The Internet and Higher Education, 8(4), 291-298. doi: 10.1016/j.iheduc.2005.09.002. 
Khan, T.M., Hassali M.A., \& Rasool S.T. (2013). A study assessing the impact of different teaching modalities for pharmacy students in a cardiopulmonary resuscitation (CPR) course. Saudi Pharmaceutical Journal, 21(4), 375-8. doi: 10.1016/j.jsps.2012.11.002.

Kiewra, K. A., Benton, S. L., \& Lewis, L. B. (1987). Qualitative aspects of note-taking and their relationship with information-processing ability and academic achievement. Journal of Instructional Psychology, 14, 110-117.

Kiewra, K. A., \& Benton, S. L. (1988). The relationship between informationprocessing ability and note-taking. Contemporary Educational Psychology, 13, 33-44. doi: 10.1016/0361-476X(88)90004-5.

Kiewra, K. A. (1989). A review of note-taking: The encoding-storage paradigm and beyond. Educational Psychology Review, 1, 147-172. doi: 10.1007/BF01326640.

Kiewra, K. A., DuBois, N. F., Christian, D., \& McShane, A. (1988). Providing study notes: Comparison of three types of notes for review, Journal of Educational Psychology, 80, 595-597. doi: 10.1037/0022-0663.80.4.595.

Kiewra, K., Dubois, N., Christensen, M., Kim, S., \& Lindberg, N. (1989). A more equitable account of the note-taking functions in learning from lecture and from text. Instructional Science, 18(3), 217-232. doi: 10.1007/BF00053360.

Kiewra, K. A., DuBois, N. F., Christian, D., McShane, A., Meyerhoffer, M., \& Roskelley, D. (1991). Note taking functions and techniques. Journal of Educational Psychology, 83(2), 240-245. doi: 10.1037/0022-0663.83.2.240.

Kiewra, K. A. (1991). Aides to lecture learning. Educational Psychologist, 26, 37-53. doi: 10.1207/s15326985ep2601_3.

Kiewra, K., S. Benton, S., Kim, S., Risch, N., \& Christensen, M. (1995). Effects of note-taking format and study technique on recall and relational performance. Contemporary Educational Psychology, 20(2), 172-187. doi: 10.1006/ceps.1995.1011.

Kinshuk, Liu, T., \& Graf, S. (2009). Coping with mismatched courses: Students' behavior and performance in courses mismatched to their learning styles. Educational Technology Res. and Development, 57(6), 739-752. doi: 10.1007/s11423-009-9116-y

Kintsch, W. (1998). Comprehension: A paradigm for cognition. Cambridge, England: Cambridge University Press.

Kobayashi, K. (2006). Combined effects of note-taking/-reviewing on learning and the enhancement through interventions: A meta-analytic review. Educational Psychology, 26(3), 459-477. doi: 10.1080/01443410500342070

Laidlaw, E. N., Skok, R. L., \& McLaughlin, T. F. (1993). The effects of notetaking and self-questioning on quiz performance. Science and Education, 77, 75-82. doi: 10.1002/sce.3730770105. 
Lonka, K. (1997). Explorations of constructive processes in student learning. Academic Dissertation. University of Helsinky, Helsinky.

Makany, T., Kemp, J., \& Dror, I. (2008). Optimizing the use of note-taking as an external cognitive aid for increasing learning. British Journal of Educational Technology, 40, 619-635. doi:10.1111/j.1467-8535.2008.00906.x.

Moos, D. C. (2009). Note-taking while learning with hypermedia: Cognitive and motivational considerations. Computers in Human Behavior, 25, 1120-1128. doi: 10.1016/j.chb.2009.05.004.

Moore Stacy, E. \& Cain, J. (2015). Note-taking and handouts in the digital age. American Journal of Pharmaceutical Education, 79(7), 1-6. doi: 10.5688/ajpe797107.

Mueller, P. A., \& Oppenheimer, D. M. (2014). The pen is mightier than the keyboard: Advantages of longhand over laptop note taking. Psychological Science, 25, 1159-1168. doi: 10.1177/0956797614524581.

Olive, T. (2012). Writing and working memory: A summary of theories and of findings. In E. Grigorenko, E. Mambrino, \& D. Preiss (Eds.), Handbook of writing: A mosaic of new perspectives (pp.125-140). New York: Psychology Press.

Olive, T., \& Piolat, A. (2002). Suppressing visual feedback in written composition: Effects on processing demands and coordination of the writing processes. International Journal of Psychology, 37, 209-218. doi: 10.1080/00207590244000089.

Olive, T. \& Passerault, J. M. (2012). The visuospatial dimension of writing. Written Communication, 29, 326-344. doi: 10.1177/0741088312451111.

Peverly, S. T., Brobst, K. E., Graham, M., \& Shaw, R. (2003). College adults are not good at self-regulation: A study on the relationship of self-regulation, note taking, and test taking. Journal of Educational Psychology, 95, 335-346. doi: 10.1037/00220663.95.2.335.

Peverly, S. T., Ramaswamy, V., Brown, C., Sumowski, J., Alidoost, M., \& Garner, J. (2007). What predicts skill in lecture note taking? Journal of Educational Psychology, 99(1), 167-180. doi: 10.1037/0022-0663.99.1.167.

Peverly, S. T., \& Sumowski, J. F. (2011). What variables predict quality of text notes and are text notes related to performance on different types of tests? Text notetaking. Applied Cognitive Psychology, 26(1), 104-117. doi: 10.1002/acp.1802.

Piolat, A., Olive, T., \& Kellogg, R. T. (2005). Cognitive effort during note taking. Applied Cognitive Psychology, 19, 291-312. doi: 10.1002/acp.1086.

Prince, M. (2004). Does active learning work? A review of the research. Journal of Engineering Education, 93(3), 223-231. doi: 10.1002/j.2168-9830.2004.tb00809.x.

Slotte, V., \& Lonka, K. (1999). Review and process effects of spontaneous notetaking on text comprehension. Contemporary Educational Psychology, 24, 1-20. doi: 10.1006/ceps.1998.0980. 
Spires, H. A. (1993). Learning from a lecture: Effects of comprehension monitoring. Reading Research \& Instruction, 32(2), 19-30. doi: 10.1080/19388079309558113.

Steimle, J., Brdiczka, O., \& Mühlhäuser, M. (2009). Collaborative paper-based annotation of lecture slides. Educational Technology and Society, 12, 125-137.

Sutton, P. (2000). Using lecture notes on the Internet as learning support materials for lectures: Student and staff perspectives on note-taking. Psychology Teaching Review, 9(1), 26-37.

Stefanou, C., Hoffman L., \& Vielee, N. (2008). Note-taking in the college classroom as evidence of generative learning. Learning Environ Res, 11, 1-17. doi: 10.1007/s10984007-9033-0.

Suritsky, S. K. (1993). Note taking approaches and specific areas of difficulty reported by university students with learning disabilities. Journal of Postsecondary Education and Disability, 10(1), 3-10.

Trafton, J. G., \& Trickett, S. B. (2001). Note-Taking for Self-Explanation and Problem Solving. Human-Computer Interaction, 16, 1-38. doi: 10.1207/S15327051HCI1601_1.

Trevors, G., Duffy, M., \& Azevedo, R. (2014). Note-taking within MetaTutor: Interactions between an intelligent tutoring system and prior knowledge on note-taking and learning. Educational Technology Research and Development, 62(5), 507-528. doi: 10.1007/s11423-014-9343-8.

Van der Meer, J. (2012). Students' note-taking challenges in the twenty-first century: considerations for teachers and academic staff developers. Teaching in Higher Education, 17(1), 13-23. doi: 10.1080/13562517.2011.590974.

Van Meter, P., Yokoi, L., \& Pressley, M. (1994). College students' theory of notetaking derived from their perceptions of note-taking. Journal of Educational Psychology, 86, 323-338. doi: 10.1037/0022-0663.86.3.323.

Weiss, I. R. (2002). A national convocation on professional development for mathematics and science teachers, $K-12$. Washington, DC: Horizon Research.

Williams, R. L., \& Eggert, A. C. (2002). Note-taking in college classes: Student patterns and instructional strategies. Journal of General Education, 51(3), 73-199. doi: 10.1353/jge.2003.0006. 